\title{
The role of cystatin- $C$ in the confirmation of reduced glomerular filtration rate among the oldest old
}

Lisandro D. Colantonio ${ }^{1}$, Rikki M. Tanner ${ }^{1}$, David G. Warnock², Orlando M. Gutiérrez ${ }^{1,2}$, Suzanne Judd ${ }^{3}$, Paul Muntner ${ }^{1,2}$, C. Barrett Bowling ${ }^{4,5}$

${ }^{1}$ Department of Epidemiology, University of Alabama at Birmingham, Birmingham, AL, USA

2Department of Medicine, University of Alabama at Birmingham, Birmingham, AL, USA ${ }^{3}$ Department of Biostatistics, University of Alabama at Birmingham, Birmingham, AL, USA

${ }^{4}$ Birmingham/Atlanta Geriatric Research, Education, and Clinical Center,

Atlanta Veterans Affairs Medical Center, Decatur, GA, USA

${ }^{5}$ Department of Medicine, Emory University, Atlanta, GA, USA

Submitted: 5 May 2015

Accepted: 28 July 2015

Arch Med Sci 2016; 12, 1: 55-67

DOI: 10.5114 /aoms.2016.57580

Copyright $\odot 2016$ Termedia \& Banach

\section{Abstract}

Introduction: Current guidelines suggest using cystatin- $C$ to confirm a reduced creatinine-based estimated glomerular filtration rate $\left(e G F R_{c r}\right)$ when the latter is thought to be inaccurate. Older adults have reduced muscle mass, which may affect the accuracy of eGFR. We evaluated the use of cystatin-C-based eGFR (eGFR ${ }_{\text {cys }}$ ) to confirm reduced eGFR cr among adults $\geq 80$ years of age and, for comparison, younger adults.

Material and methods: We analyzed data from 3,059 REasons for Geographic And Racial Differences in Stroke (REGARDS) study participants with reduced eGFR $_{\text {cr }}\left(<60 \mathrm{ml} / \mathrm{min} / 1.73 \mathrm{~m}^{2}\right)$ enrolled in 2003-2007 who were not on dialysis. eGFR and eGFR $\mathrm{C}_{\text {cys }}$ were calculated using age, sex and race-adjusted equations. Confirmed reduced eGFR cr $_{\text {was defined as eGFR }}<60 \mathrm{ml} /$ $\mathrm{min} / 1.73 \mathrm{~m}^{2}$. Prevalence of chronic kidney disease complications at baseline and all-cause mortality up to March 2012 were calculated. Analyses were stratified by age: $<65,65-79$ and $\geq 80$ years.

Results: Among participants $<65,65-79$ and $\geq 80$ years of age, $76.5 \%$, $85.7 \%$ and $92.5 \%$, respectively, had reduced eGFR cr confirmed with eGFR $_{\text {cys }}$ $(p<0.001)$. Among participants $\geq 80$ years of age, those with reduced eGFR $_{\text {cr }}$ confirmed with eGFR cys had higher prevalence of hypertension $(79.1 \%$ vs. $65.1 \%, p=0.03$ ) and albuminuria (38.3\% vs. $22.7 \%, p=0.04)$ and higher risk for all-cause mortality (hazard ratio: 2.43 ; $95 \%$ confidence interval: 1.19-5.01) as compared with those in whom reduced eGFR cr was not confirmed by eGFR

Conclusions: Reduced eGFR cr was confirmed using eGFR cys $_{\text {cr }}$ for the vast majority of adults $\geq 80$ years. These results suggest that using cystatin- $C$ to confirm a reduced eGFR cr may not be necessary among the oldest old.

Key words: aged, 80 and over, kidney function tests, renal insufficiency, chronic, mortality.

\section{Introduction}

The number of US adults 80 years and older (hereafter, the oldest old) with reduced estimated glomerular filtration rate (eGFR, $<60 \mathrm{ml} /$ $\mathrm{min} / 1.73 \mathrm{~m}^{2}$ ) has increased over the last 20 years and is expected to

\author{
Corresponding author: \\ C. Barrett Bowling MD, MSPH \\ Atlanta VAMC \\ 1670 Clairmont Road (11B) \\ Decatur, GA, 30033, USA \\ Phone: (404) 321-6111 \\ Fax: (404) 728-7779 \\ E-mail: cbbowli@emory.edu
}


more than double to 9.9 million people by 2030 $[1,2]$. Despite studies showing associations of reduced eGFR with increased risk for mortality, cardiovascular disease and concurrent chronic kidney disease (CKD) complications [3-7], questions remain about the use of creatinine-based equations alone to estimate GFR and define CKD in this population [8].

The 2012 Kidney Disease: Improving Global Outcomes (KDIGO) Clinical Practice Guideline for the Evaluation and Management of CKD recommends using creatinine-based equations for initial assessment of CKD [9]. The guideline also suggests using serum cystatin- $C$ as an additional test in circumstances when estimations based on serum creatinine are thought to be inaccurate [9]. Sarcopenia, defined as a progressive loss of skeletal muscle mass, is more common at older age $[10,11]$. Because serum creatinine is a product of muscle metabolism, sarcopenia could affect the accuracy of serum creatinine-based equations to estimate GFR [9]. Therefore, there may be a greater need to confirm reduced eGFR based on serum creatinine among the oldest old.

In the current study, we estimated the percentage of the oldest old with reduced eGFR calculated using serum creatinine confirmed with serum cystatin-C eGFR. For comparison, this percentage was also calculated for younger adults. We hypothesized that among individuals with reduced serum creatinine-based eGFR, the percentage with reduced eGFR based on serum cystatin-C would be lower among the oldest old compared with younger adults. In addition, we compared the prevalence of concurrent CKD complications and risk for allcause mortality among adults with serum creatinine-based reduced eGFR confirmed versus not confirmed by serum cystatin-C-based eGFR by age group. For completeness, we also analyzed the use of serum cystatin- $C$ for the confirmation of a preserved eGFR based on serum creatinine.

\section{Material and methods}

\section{Study population}

We used data from the REasons for Geographic And Racial Differences in Stroke (REGARDS) study, a US population-based prospective cohort study designed to investigate reasons underlying the higher rate of stroke mortality among blacks compared with whites and residents of the Southeastern US compared with the rest of the continental US [12]. A total of 30,239 black and white men and women aged 45 years or older were recruited from all 48 contiguous US states and the District of Columbia between January 2003 and October 2007. Blacks and residents of the Southeastern US were oversampled by design. For the present analysis, we included participants who were not on dialysis, had measurements of serum creatinine and cystatin- $C$ at baseline, and follow-up information on all-cause mortality. A total of 27,528 REGARDS participants met the inclusion criteria (Figure 1). The REGARDS study was approved by the institutional review boards at the participating centers and all participants provided written informed consent.

\section{Baseline assessment}

REGARDS baseline data were collected through a telephone interview followed by an in-home examination, each performed by trained staff and following standardized protocols. Self-reported information collected during the telephone interview at baseline included age, race, gender, education, physical activity, current cigarette smoking,

Participants included in the REGARDS study $(n=30,239)$

Total exclude from the analysis ( $n=2,711)$

Reason for exclusion:

Missing data on serum creatinine $(n=1,305)$

Missing data on serum cystatin-C $(n=814)$

On dialysis $(n=87)$

Missing follow-up for mortality $(n=505)$

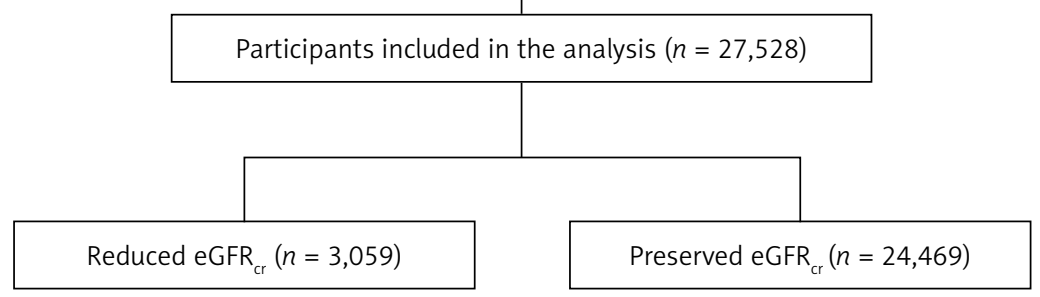

Figure 1. Flow-chart of REGARDS participants included in the study

eGFR - estimated glomerular filtration rate using serum creatinine, REGARDS - REasons for Geographic And Racial Differences in Stroke. Reduced eGFR was defined as eGFR $<60 \mathrm{ml} / \mathrm{min} / 1.73 \mathrm{~m}^{2}$. Preserved eGFR was defined as eGFR $\geq 60 \mathrm{ml} / \mathrm{min} / 1.73 \mathrm{~m}{ }^{2}$. 
history of stroke and use of antihypertensive medications. During the in-home examination, blood pressure, weight, height and waist circumference were measured, an electrocardiogram was recorded, and blood and urine samples were collected. Prescription and over-the-counter medications used in the 2 weeks prior to the in-home examination were reviewed and recorded.

History of coronary heart disease (CHD) was defined by self-report of a prior diagnosis or evidence of a previous myocardial infarction (MI) on the study electrocardiogram, coronary bypass, coronary angioplasty, or coronary stenting. Diabetes was defined as self-reported treatment with oral antidiabetes medication or insulin, fasting ( $\geq 8 \mathrm{~h}$ ) serum glucose $\geq 126 \mathrm{mg} / \mathrm{dl}$ or non-fasting serum glucose $\geq 200 \mathrm{mg} / \mathrm{dl}$. High waist circumference was defined as $>102 \mathrm{~cm}$ among males and $>88 \mathrm{~cm}$ among females. Body mass index (BMI) was calculated as weight in $\mathrm{kg} /$ (height in meters) $^{2}$, and categorized as < 18.5, 18.5 to < 25.0, 25.0 to $<30.0$ and $\geq 30.0 \mathrm{~kg} / \mathrm{m}^{2}$. Use of statins was defined based on the in-home review of medications.

\section{Glomerular filtration rate}

Serum creatinine and cystatin- $C$ were measured using blood samples collected during the baseline in-home assessment. Serum creatinine was measured and calibrated using an isotope-dilution mass spectrometry traceable method [4]. Cystatin- $C$ was measured using a particle-enhanced immunonephelometric assay ( $N$ Latex Cystatin C, formerly Dade Behring, now Siemens AG, Munich, Germany). For each participant, eGFR was calculated using serum creatinine (eGFR ${ }_{c r}$ ) and, separately, using serum cystatin-C (eGFR ${ }_{\text {cys }}$ ) and the age, race, sex Chronic Kidney Disease Epidemiology Collaboration (CKD-EPI) equations [13]. eGFR ${ }_{c r}$ and eGFR ${ }_{\text {cys }}$ were each categorized as preserved $\left(G F R \geq 60 \mathrm{ml} / \mathrm{min} / 1.73 \mathrm{~m}^{2}\right)$ or reduced (<60 ml/min/1.73 $\mathrm{m}^{2}$ ). Also, we calculated eGFR using a CKD-EPI equation that includes the combination of serum creatinine and cystatin- $C$ $\left(\mathrm{eGFR}_{\text {cr,ys }}\right)$ and the two versions of the Berlin Initiative Study (BIS) equation (eGFR $\mathrm{BIS}_{1}$ and eGFR $\mathrm{BIS2}_{2}$ ) $[13,14]$. Table I shows the equations used for the present analysis.

\section{Concurrent CKD complications and all-cause mortality}

Concurrent CKD complications considered for the present analysis included hypertension, serum albumin concentration < $3.8 \mathrm{~g} / \mathrm{dl}$, anemia, high-sensitivity C-reactive protein (hsCRP) $>3 \mathrm{mg} / \mathrm{l}$ and urinary albumin-to-creatinine ratio $(A C R)>30 \mathrm{mg} / \mathrm{g}$. Blood pressure was measured

Table I. Equations used to calculate estimated glomerular filtration rate

\begin{tabular}{|c|c|c|c|c|}
\hline eGFR & Gender & $\begin{array}{l}\text { Scys } \\
{[\mathrm{mg} / \mathrm{l}]}\end{array}$ & $\begin{array}{c}\mathrm{Scr} \\
{[\mathrm{mg} / \mathrm{dl}]}\end{array}$ & Equation \\
\hline \multirow[t]{4}{*}{$\mathrm{eGFR}_{\mathrm{cr}}[13]^{\mathrm{a}}$} & Female & - & $\leq 0.7$ & $144 \times(\mathrm{Scr} / 0.7)^{-0.329} \times 0.993^{\mathrm{Age}}[\times 1.159$ if black $]$ \\
\hline & Female & - & $>0.7$ & $144 \times(\mathrm{Scr} / 0.7)^{-1.209} \times 0.993^{\mathrm{Age}}[\times 1.159$ if black $]$ \\
\hline & Male & - & $\leq 0.9$ & $141 \times(\mathrm{Scr} / 0.9)^{-0.411} \times 0.993^{\mathrm{Age}}[\times 1.159$ if black $]$ \\
\hline & Male & - & $>0.9$ & $141 \times(\mathrm{Scr} / 0.9)^{-1.209} \times 0.993^{\mathrm{Age}}[\times 1.159$ if black $]$ \\
\hline \multirow[t]{2}{*}{$\mathrm{eGFR}_{\mathrm{cys}}[13]$} & - & $\leq 0.8$ & - & $133 \times(\text { Scys } / 0.8)^{-0.499} \times 0.996^{\text {Age }}[\times 0.932$ if female $]$ \\
\hline & - & $>0.8$ & - & $133 \times(\text { Scys } / 0.8)^{-1.328} \times 0.996^{\text {Age }}[\times 0.932$ if female $]$ \\
\hline \multirow[t]{8}{*}{$\mathrm{eGFR}_{\mathrm{cr}, \mathrm{cys}}[13]$} & Female & $\leq 0.8$ & $\leq 0.7$ & $130 \times(\mathrm{Scr} / 0.7)^{-0.248} \times(\mathrm{Scys} / 0.8)^{-0.375} \times 0.995^{\mathrm{Age}}[\times 1.08$ if black $]$ \\
\hline & Female & $\leq 0.8$ & $>0.7$ & $130 \times(\mathrm{Scr} / 0.7)^{-0.601} \times(\mathrm{Scys} / 0.8)^{-0.375} \times 0.995^{\mathrm{Age}}[\times 1.08$ if black $]$ \\
\hline & Female & $>0.8$ & $\leq 0.7$ & $130 \times(\mathrm{Scr} / 0.7)^{-0.248} \times(\mathrm{Scys} / 0.8)^{-0.711} \times 0.995^{\text {Age }}[\times 1.08$ if black $]$ \\
\hline & Female & $>0.8$ & $>0.7$ & $130 \times(\mathrm{Scr} / 0.7)^{-0.601} \times(\mathrm{Scys} / 0.8)^{-0.711} \times 0.995^{\mathrm{Age}}[\times 1.08$ if black $]$ \\
\hline & Male & $\leq 0.8$ & $\leq 0.9$ & $135 \times(\mathrm{Scr} / 0.9)^{-0.207} \times(\mathrm{Scys} / 0.8)^{-0.375} \times 0.995^{\mathrm{Age}}[\times 1.08$ if black $]$ \\
\hline & Male & $\leq 0.8$ & $>0.9$ & $135 \times(\mathrm{Scr} / 0.9)^{-0.601} \times(\mathrm{Scys} / 0.8)^{-0.375} \times 0.995^{\mathrm{Age}}[\times 1.08$ if black $]$ \\
\hline & Male & $>0.8$ & $\leq 0.9$ & $135 \times(\mathrm{Scr} / 0.9)^{-0.207} \times(\mathrm{Scys} / 0.8)^{-0.711} \times 0.995^{\mathrm{Age}}[\times 1.08$ if black $]$ \\
\hline & Male & $>0.8$ & $>0.9$ & $135 \times(\mathrm{Scr} / 0.9)^{-0.601} \times(\mathrm{Scys} / 0.8)^{-0.711} \times 0.995^{\mathrm{Age}}[\times 1.08$ if black $]$ \\
\hline $\mathrm{eGFR}_{\mathrm{BIS1} 1}[14]$ & - & - & - & $3736 \times \mathrm{Scr}^{-0.87} \times \mathrm{Age}^{-0.95}[\times 0.82$ if female $]$ \\
\hline $\mathrm{eGFR}_{\mathrm{BIS2}}[14]$ & - & - & - & $767 \times$ Scys $^{-0.61} \times \mathrm{Scr}^{-0.40} \times \mathrm{Age}^{-0.57}[\times 0.87$ if female $]$ \\
\hline
\end{tabular}

BIS - Berlin Initiative Study, eGFR - estimated glomerular filtration rate, Scr - serum creatinine, Scys - serum cystatin-C. ${ }^{a}$ This equation is also known as the CKD-EPI equation. 
twice during the in-home study visit following a 5 -minute rest. Based on the average of the two measurements, hypertension was defined as systolic blood pressure $\geq 140 \mathrm{~mm} \mathrm{Hg}$, diastolic blood pressure $\geq 90 \mathrm{~mm} \mathrm{Hg}$, or self-reported use of antihypertensive medications. Anemia was defined as hemoglobin concentration $<13.0$ and $<12.0 \mathrm{~g} / \mathrm{dl}$ for males and females, respectively [15].

REGARDS participants or their proxies are contacted by telephone every 6 months following the baseline study visit to determine vital status. Reported deaths and the date of death were confirmed through the Social Security Death Index, death certificates, or the National Death Index. For the current analysis, data on mortality for REGARDS participants up to March 29, 2012 were analyzed.

\section{Statistical analysis}

All analyses were conducted stratified by age: (1) < 65 years, (2) 65 to 79 years, and ( 3 ) $\geq 80$ years of age. The main analyses were limited to participants with reduced $\mathrm{eGFR}_{\mathrm{cr}}$. Among this group, participants with eGFR $_{\text {cys }}<60 \mathrm{ml} / \mathrm{min} / 1.73 \mathrm{~m}^{2}$ were considered to have confirmed reduced eG$F R_{c r}$. We calculated baseline characteristics of participants whose reduced GGFR $_{\text {cr }}$ was confirmed and not confirmed using eGFR ${ }_{\text {cys }}$. The percentage of participants with confirmed reduced $\mathrm{eGFR}_{\mathrm{cr}}$ across age strata was compared using a $\chi^{2}$ test.

Table II. Missing data among REGARDS participants included in the analysis $(n=27,528)$. These data were imputed using chained equations

\begin{tabular}{|c|c|}
\hline Variable $^{a}$ & $N$ missing (\%) \\
\hline Less than high school & $21(0.1)$ \\
\hline No physical activity & $417(1.5)$ \\
\hline Current smoking & $101(0.4)$ \\
\hline History of CHD & $493(1.8)$ \\
\hline History of stroke & $90(0.3)$ \\
\hline Diabetes & $140(0.5)$ \\
\hline Waist circumference & $150(0.5)$ \\
\hline \multicolumn{2}{|l|}{ Concurrent CKD complications: } \\
\hline Hypertension & $67(0.2)$ \\
\hline Serum albumin $<3.8 \mathrm{~g} / \mathrm{dl}$ & $7,561(27.5)$ \\
\hline Anemia & $8,438(30.7)$ \\
\hline $\mathrm{hsCRP}>3 \mathrm{mg} / \mathrm{l}$ & $12(<0.1)$ \\
\hline$A C R>30 \mathrm{mg} / \mathrm{g}$ & $898(3.3)$ \\
\hline \multicolumn{2}{|c|}{$\begin{array}{l}\text { ACR - albumin : creatinine ratio, CHD - coronary heart disease, } \\
\text { hSCRP - high sensibility C-reactive protein, REGARDS - REasons } \\
\text { for Geographic And Racial Differences in Stroke. aOnly variables } \\
\text { with missing data are listed. The remainder of variables studied } \\
\text { had no missing data. Hypertension was defined as systolic blood } \\
\text { pressure } \geq 140 \mathrm{~mm} \mathrm{Hg} \text {, diastolic blood pressure } \geq 90 \mathrm{~mm} \mathrm{Hg} \text {, or } \\
\text { self-reported use of antihypertensive medications. Anemia was } \\
\text { defined as hemoglobin concentration }<13.0 \mathrm{~g} / \mathrm{dl} \text { and }<12.0 \mathrm{~g} / \mathrm{dl} \\
\text { for males and females, respectively [15]. }\end{array}$} \\
\hline
\end{tabular}

In addition, we calculated the percentage of participants whose reduced eGFR $_{c r}$ was confirmed using eGFR ${ }_{\mathrm{cr}, \mathrm{cys}}, \mathrm{eGFR}_{\mathrm{BIS} 1}$ and eGFR $\mathrm{BIS2}_{\mathrm{cr}}$. Among participants $\geq 80$ years of age, we calculated the percentage whose reduced eGFR cr $_{\text {was confirmed }}$ using eGFR cys by level of waist circumference and, separately, BMI.

We calculated the prevalence of concurrent CKD complications among participants with and without confirmed reduced $\mathrm{eGFR}_{\mathrm{cr}}$, separately. Differences in the prevalence of concurrent CKD complications across these categories were determined using maximum likelihood. We used the Kaplan-Meier method to estimate cumulative mortality for participants with and without confirmed eGFR $_{c r}$ with the statistical significance of differences determined using log-rank tests. Hazard ratios (HRs) for all-cause mortality comparing participants with versus without confirmed eGFR were estimated using Cox proportional hazard models. Three progressively multivariable adjusted Cox proportional hazard models were used. Model 1 included adjustment for age, race, gender, region of residence and eGFR cr. Model 2 included adjustment for variables in Model 1 plus education level, physical activity, smoking, history of CHD, history of stroke, diabetes, waist circumference and statin use. Model 3 included adjustment for variables in Model 2 and hypertension, serum albumin $<3.8 \mathrm{~g} /$ $\mathrm{dl}$, anemia, hsCRP > $3 \mathrm{mg} / \mathrm{l}$ and ACR > $30 \mathrm{mg} / \mathrm{g}$. In a regression model including all age groups and interaction terms, we assessed whether the HRs for all-cause mortality were different across age groups.

For completeness, we conducted analyses to confirm preserved eGFR . For this secondary analysis, the percentage of participants whose preserved eGFR ${ }_{c r}$ (i.e., eGFR cr $\geq 60 \mathrm{ml} / \mathrm{min} / 1.73 \mathrm{~m}^{2}$ ) was confirmed using eGFR cys $_{\text {(i.e., }} \mathrm{eGFR}_{\text {cys }} \geq 60 \mathrm{ml}$ $\min / 1.73 \mathrm{~m}^{2}$ ), and separately using $\mathrm{eGFR}_{\text {cr,cys }}$, $\mathrm{eGFR}_{\mathrm{BIS1}}$ and $\mathrm{GGF}_{\mathrm{BIS2}}$, was calculated by age group. Among participants $\geq 80$ years of age, we calculated the percentage whose preserved eGFR cr was confirmed using eGFR by waist circumference and BMI, separately. Also, prevalence of concurrent CKD complications and HRs for all-cause mortality were estimated comparing participants whose preserved eGFR ${ }_{c r}$ was confirmed versus not confirmed using eGFR ${ }_{\text {cys }}$.

Because a substantial proportion of REGARDS participants do not have baseline information on serum albumin and hemoglobin (Table II), we used multiple imputation when estimating the prevalence of concurrent CKD complications as well as multivariable adjusted HRs for all-cause mortality. For these analyses, we imputed 10 data sets using chained equations. Multiple imputation was based on observed values from all the variables included in the fully adjusted Cox regression model (Model 3) and all-cause mortality $[16,17]$. 
All analyses were conducted using Stata/I.C. 13.1 (Stata Corporation, College Station, TX) and a 2-sided level of significance of $\alpha<0.05$.

\section{Results}

\section{Confirmation of reduced eGFR}

A total of 3,059 (11.1\%) participants included in the analysis had reduced eGFR at baseline. Among participants with reduced eGFR ${ }_{\mathrm{c}}$, a higher percentage was confirmed using eGFR among those $\geq 80$ years of age as compared with younger adults (Figure 2). The percentage whose reduced

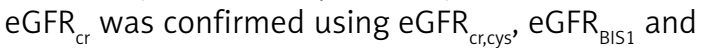
$\mathrm{eGFR}_{\mathrm{BIS}}$ was also higher among those $\geq 80$ years of age (Table III). Among those $\geq 80$ years of age, the percentage whose reduced eGFR $\mathrm{cr}_{\mathrm{cr}}$ was confirmed by eGFR $_{\text {cys }}$ was similar when stratified by waist circumference or BMI (Figure 3). Baseline characteristics of REGARDS participants whose reduced eGFR $R_{c r}$ was confirmed versus not confirmed using eGFR ${ }_{\text {cys }}$ are provided by age in Table IV.

Among participants $\geq 80$ years of age, those whose reduced eGFR $\mathrm{c}_{\mathrm{cr}}$ was confirmed using eGFR had a higher prevalence of hypertension and ACR $>30 \mathrm{mg} / \mathrm{g}$ (Table V). Although presence of serum albumin $<3.8 \mathrm{~g} / \mathrm{dl}$, anemia and $\mathrm{hsCRP}>3 \mathrm{mg} / \mathrm{l}$ were each more common among individuals whose reduced $\mathrm{GFR}_{\mathrm{cr}}$ was confirmed versus not confirmed using eGFR ${ }_{c y s}$, these differences were

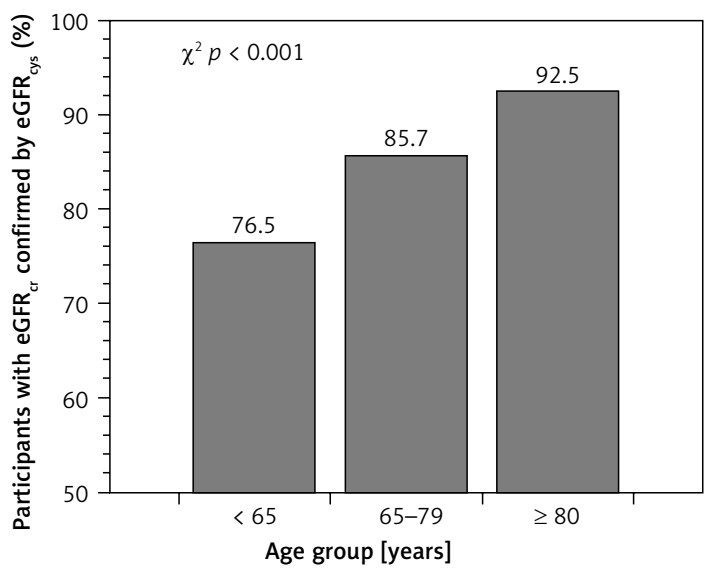

Figure 2. Percentage of REGARDS participants with reduced eGFR frr $_{\text {fr }}$ whom this result was confirmed using eGFR ${ }_{\text {cys }}$ stratified by age

$e G F R_{c r}$ - estimated glomerular filtration rate using serum creatinine, eGFR - estimated glomerular filtration rate using serum cystatin-C, REGARDS - REasons for Geographic And Racial Differences in Stroke. Reduced eGFR was defined as eGFR $<60 \mathrm{ml} / \mathrm{min} / 1.73 \mathrm{~m}^{2}$.

Table III. Percentage of REGARDS participants whose reduced eGFR ${ }_{\mathrm{Cr}}$ was confirmed using eGFR $\mathrm{Cr}_{\mathrm{Cr}, \mathrm{ys}}, \mathrm{eGFR}_{\mathrm{BIS1}}$ or $\mathrm{eGFR}_{\mathrm{BIS2}}$ stratified by age

\begin{tabular}{|lcccc|}
\hline eGFR & $<65$ years $(n=599)$ & 65 to 79 years $(n=1,805)$ & $\geq 80$ years $(n=655)$ & \multirow{2}{*}{$P$-value } \\
\cline { 2 - 4 } & $\boldsymbol{N}(\%)$ & $\boldsymbol{N}(\%)$ & $\boldsymbol{N}(\%)$ & \\
\hline eGFR $_{\text {cr,ys }}$ & $506(84.5)$ & $1,631(90.4)$ & $629(96.0)$ & $<0.001$ \\
\hline eGFR $_{\text {BIS1 }}$ & $555(92.7)$ & $1,805(100.0)$ & $655(100.0)$ & $<0.001$ \\
\hline eGFR $_{\text {BIS2 }}$ & $359(59.9)$ & $1,670(92.5)$ & $655(100.0)$ & $<0.001$ \\
\hline
\end{tabular}

eGFR - estimated glomerular filtration rate. REGARDS - Reasons for Geographic And Racial Differences in Stroke. Reduced eGFR confirmed

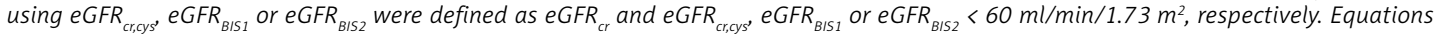

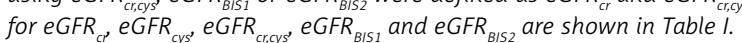
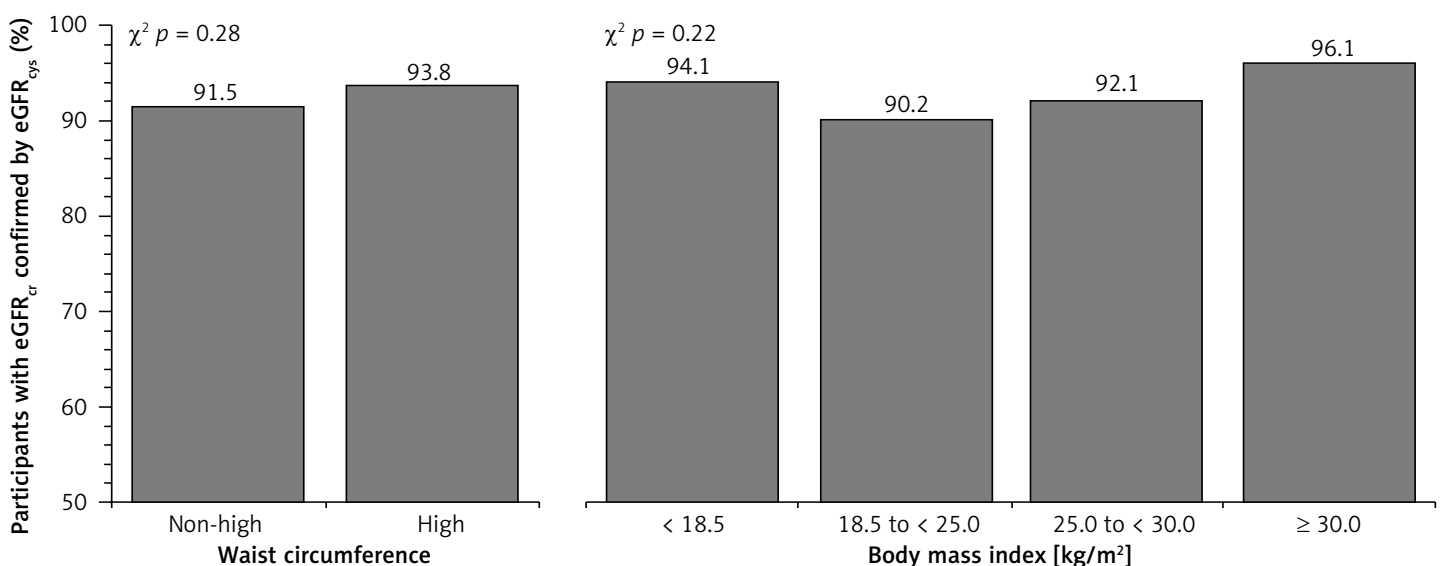

Figure 3. Percentage of REGARDS participants $\geq 80$ years of age with reduced eGFR ${ }_{c r}$ for whom this result was

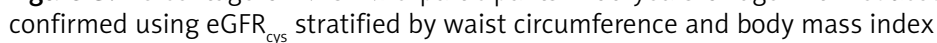

eGFR - estimated glomerular filtration rate using serum creatinine, eGFR ${ }_{c y s}$ - estimated glomerular filtration rate using serum cystatin-C, REGARDS - REasons for Geographic And Racial Differences in Stroke. Reduced eGFR was defined as eGFR <60 ml/ $\min / 1.73 \mathrm{~m}^{2}$. 


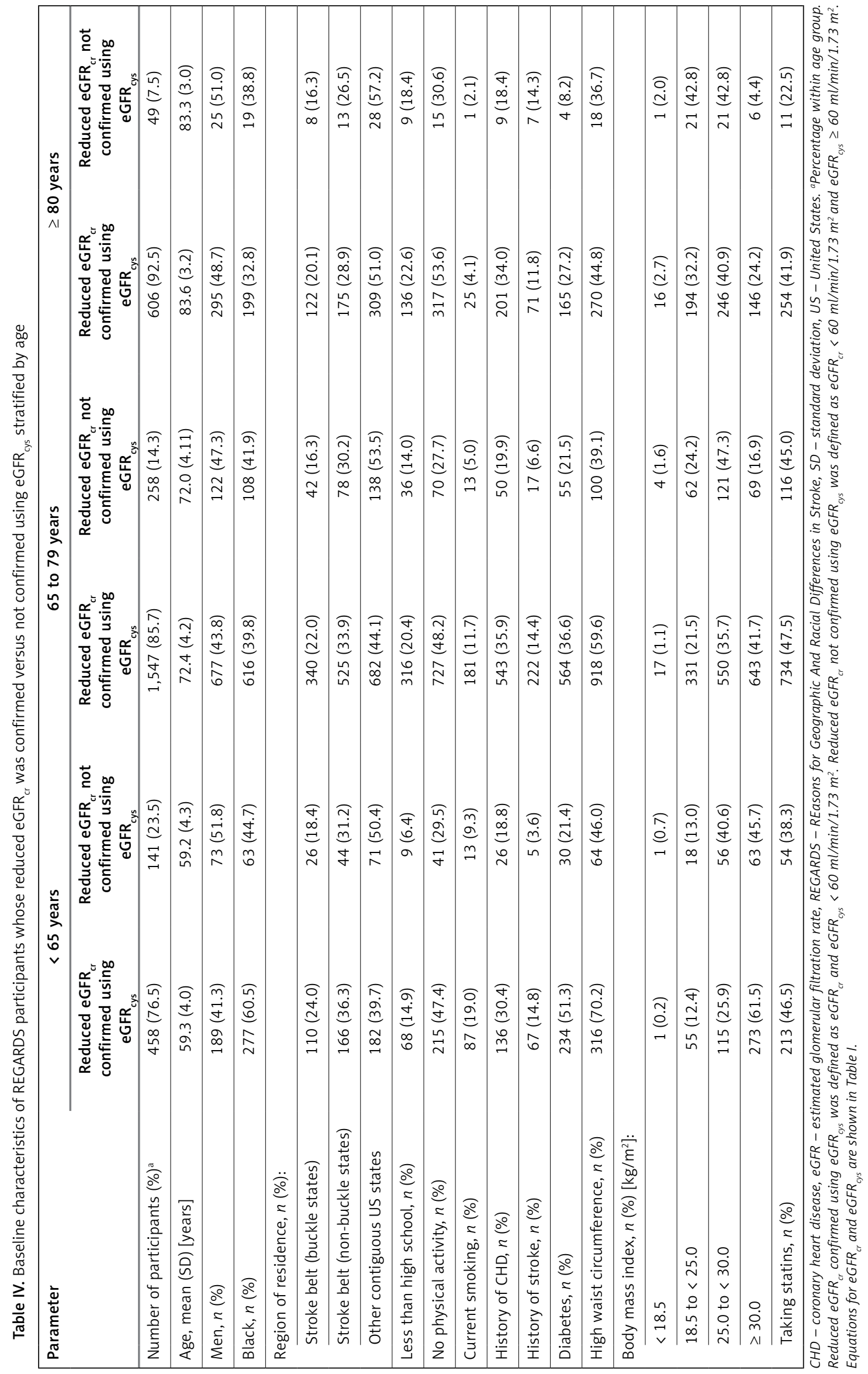




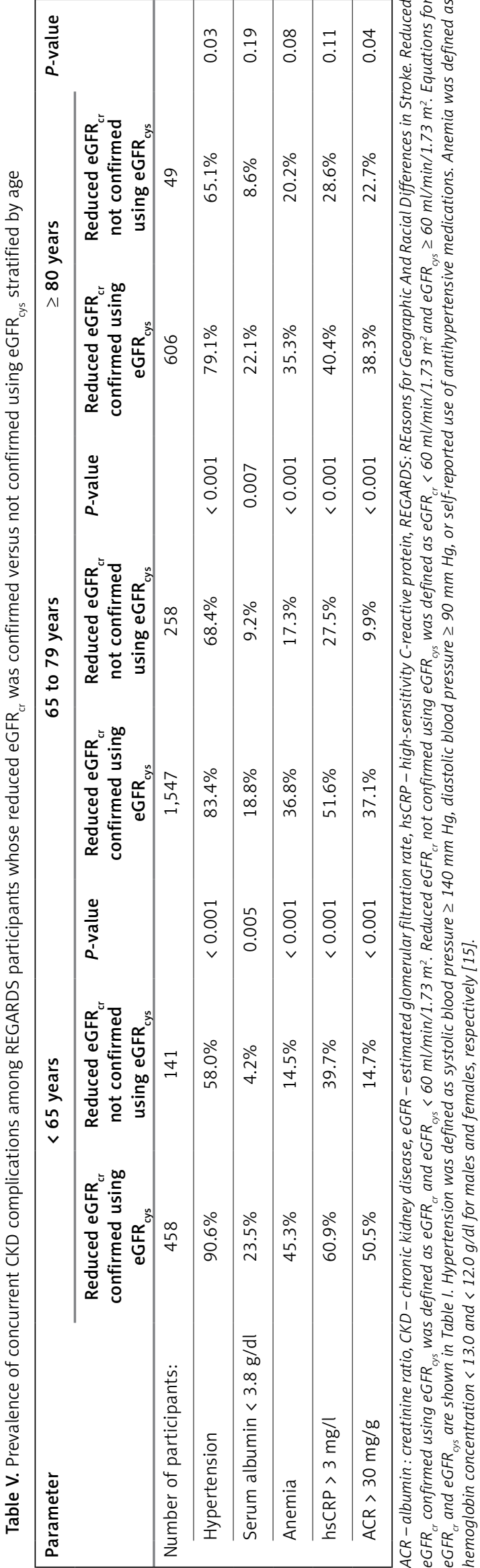

not statistically significant. Among participants $<65$ and 65 to 79 years, those whose reduced eGFR $_{\text {cr }}$ was confirmed with eGFR cys $_{\text {were more like- }}$ ly to have each concurrent CKD complication.

There were 878 deaths over 15,874 person-years of follow-up (median follow-up of 5.4 years) among REGARDS participants with reduced eGFR $_{c r}$. Within each age group, participants whose reduced eGFR ${ }_{c r}$ was confirmed using eGFR cys had higher risk for all-cause mortality as compared with their counterparts whose eGFR cr was not

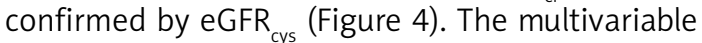

A

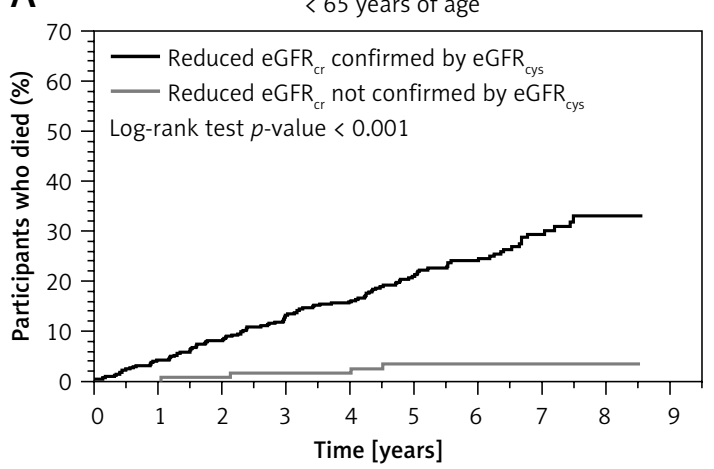

B

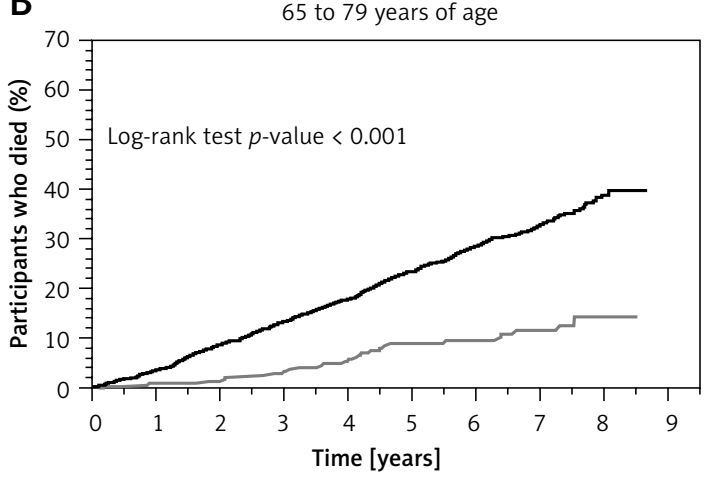

C

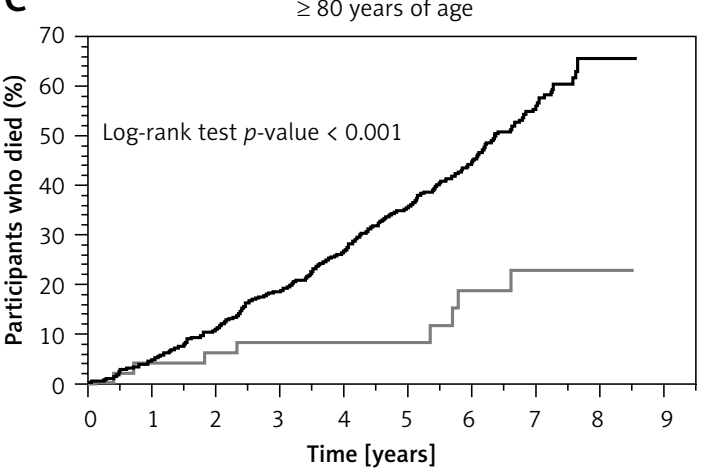

Figure 4. Cumulative mortality (Kaplan-Meier method) for REGARDS participants whose reduced eGFR $_{\text {cr }}$ was confirmed versus not confirmed using eGFR cys stratified by age

eGFR - estimated glomerular filtration rate using serum creatinine, eGFR rate using serum cystatin-C, REGARDS - REasons for Geographic And Racial Differences in Stroke. Reduced eGFR was defined as eGFR $<60 \mathrm{ml} / \mathrm{min} / 1.73 \mathrm{~m}^{2}$. 


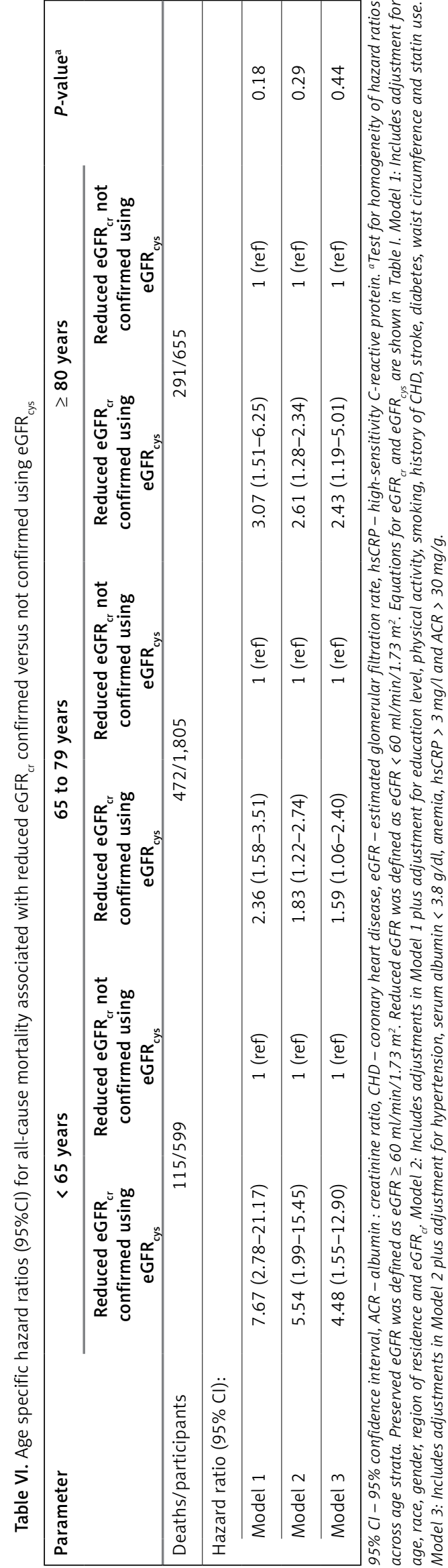

adjusted HRs $(95 \% \mathrm{Cl})$ for all-cause mortality for those whose reduced eGFR ${ }_{\mathrm{cr}}$ was confirmed versus not confirmed by eGFR cys were $4.48(1.55-12.90)$, 1.59 (1.06-2.40), and 2.43 (1.19-5.01), for those $<65$ years, 65 to 79 years, and $\geq 80$ years old, respectively (Table VI; $p$-value for homogeneity of HRs across age strata: 0.44 ).

\section{Confirmation of preserved eGFR}

Among those $<65$ years, 65 to 79 years, and $\geq 80$ years old, 12,534 (93.7\%), 7,930 (80.7\%) and 687 (54.6\%) participants, respectively, had their preserved eGFR confirmed using eGFR cys (Table VII; $p$-value for homogeneity across age strata $<0.001)$. The percentage of those whose preserved eGFR cr was confirmed using eGFR cr,cyss $_{1}$ eGFR BIS1 $_{1}$ and $\mathrm{eGFR}_{\mathrm{BIS2} 2}$ was also lower among participants $\geq 80$ years of age (Table VIII). Among those $\geq 80$ years of age, the percentage whose preserved eGFR was confirmed by eGFR cys was lower with higher waist circumference or BMI (Figure 5). Among participants $\geq 80$ years of age, those whose preserved eGFR cr was confirmed using eGFR cys had a lower prevalence of anemia, elevated hsCRP, and albuminuria (Table IX). In the younger age groups, those with preserved $\mathrm{eGFR}_{\mathrm{cr}}$ confirmed using eGFR cys had a lower prevalence of each concurrent CKD complication. Within each age group, a pre-

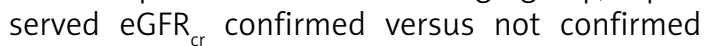
using eGFR ${ }_{\text {cys }}$ was associated with a lower HR for all-cause mortality (Table X).

\section{Discussion}

In the current study, $92.5 \%$ of participants $\geq 80$ years of age with reduced eGFR cr had reduced eGFR $_{\text {cyss }}$ as compared with $85.7 \%$ and $76.5 \%$ of those 65 to 79 and $<65$ years of age, respectively. Among participants $\geq 80$ years of age, those in whom reduced GGFR $_{\text {cr }}$ was confirmed by eGFR $_{\text {cys }}$ had a higher prevalence of several concurrent CKD complications and increased risk for all-cause mortality as compared with those in whom reduced eGFR $_{\text {cr }}$ was not confirmed. These data suggest that additional testing with cystatin- $C$ to confirm reduced eGFR may not be needed among the oldest old, since the vast majority of these individuals have reduced eGFR ${ }_{\text {cys }}$

The 2012 KDIGO Clinical Practice Guideline for the Evaluation and Management of CKD recommends using serum creatinine in calculating eGFR in clinical practice to identify individuals at high risk for concurrent CKD complications, renal disease progression, and all-cause mortality [9]. In the general population, both eGFR ${ }_{c r}$ and $\mathrm{eGFR}_{\mathrm{cys}}$ show similar performance for estimating measured GFR [13]. However, among the oldest old, eGFR may overestimate measured GFR while eGFR ${ }_{\text {cys }}$ may underestimate it. For example, in 


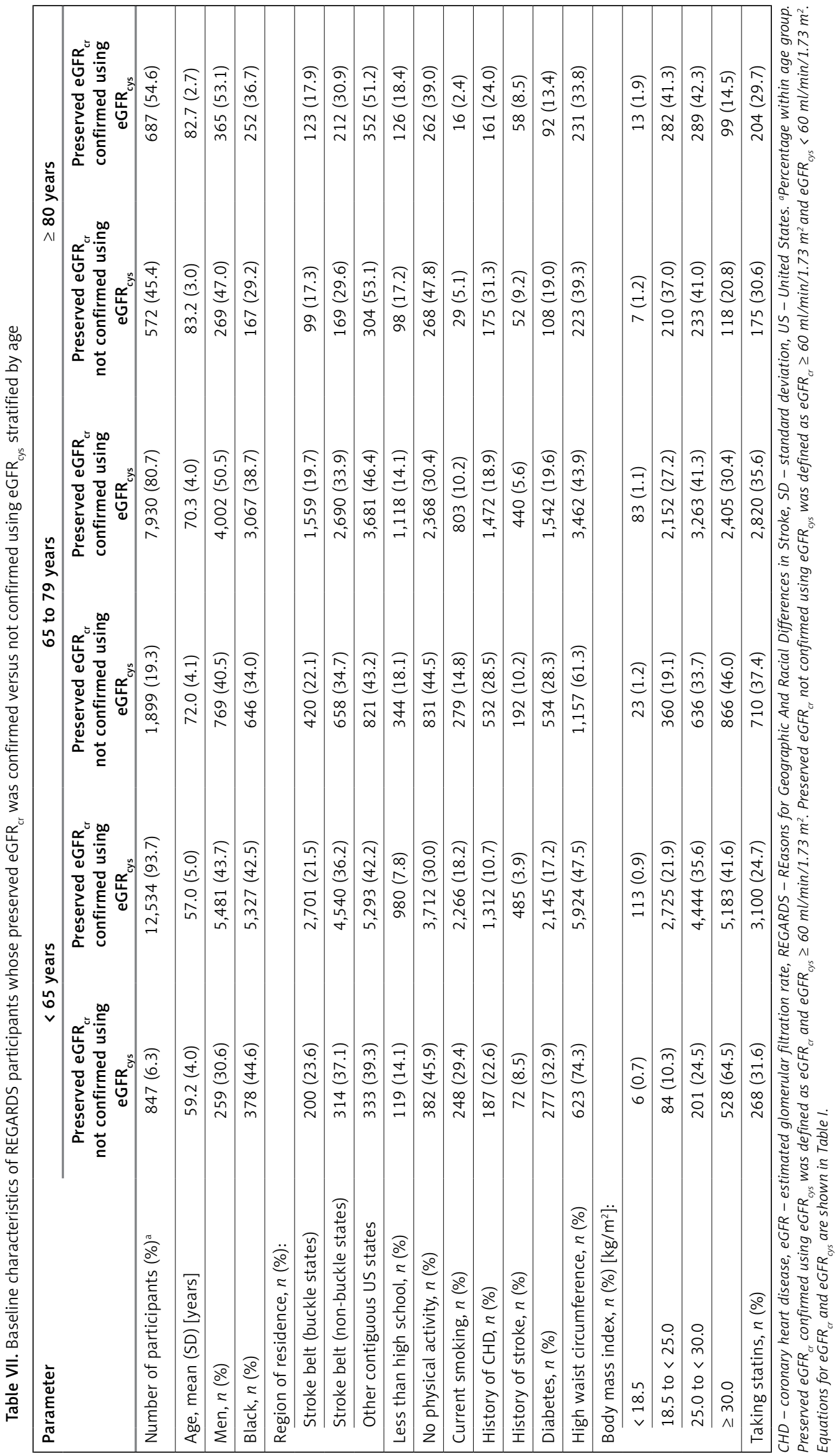


Table VIII. Percentage of REGARDS participants whose preserved eGFR ${ }_{\mathrm{cr}}$ was confirmed using eGFR $\mathrm{c}_{\mathrm{c}, \mathrm{rys}}$, $\mathrm{eGFR}_{\mathrm{BIS1}}$ or eGFR $R_{\text {BIS2 }}$ stratified by age

\begin{tabular}{|lcccc|}
\hline eGFR & $<65$ years $(n=13,381)$ & 65 to 79 years $(n=9,829)$ & $\geq 80$ years $(n=1,259)$ & \multirow{2}{*}{$P$-value } \\
\cline { 2 - 4 } & $\boldsymbol{N}(\%)$ & $\boldsymbol{N}(\%)$ & $\boldsymbol{N}(\%)$ & \\
\hline eGFR $_{\text {cr,ys }}$ & $13,077(97.7)$ & $9,088(92.5)$ & $963(76.5)$ & $<0.001$ \\
\hline eGFR $_{\text {BIS1 }}$ & $13,211(98.7)$ & $8,106(82.5)$ & $554(44.0)$ & $<0.001$ \\
\hline eGFR $_{\text {BIS2 }}$ & $13,366(99.9)$ & $9,236(94.0)$ & $775(61.6)$ & $<0.001$ \\
\hline
\end{tabular}

eGFR - estimated glomerular filtration rate, REGARDS - Reasons for Geographic And Racial Differences in Stroke. Preserved eGFR

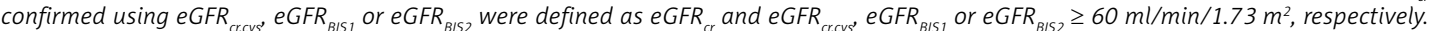

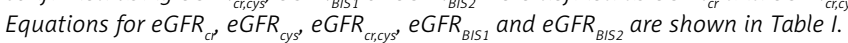

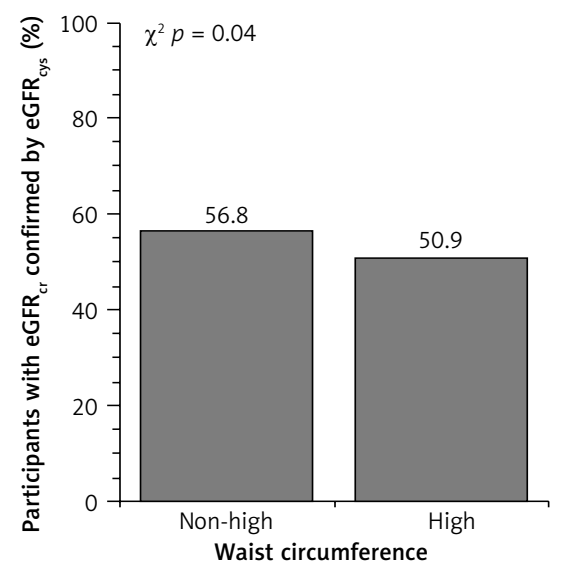

$$
\chi^{2} p=0.02
$$

65.0

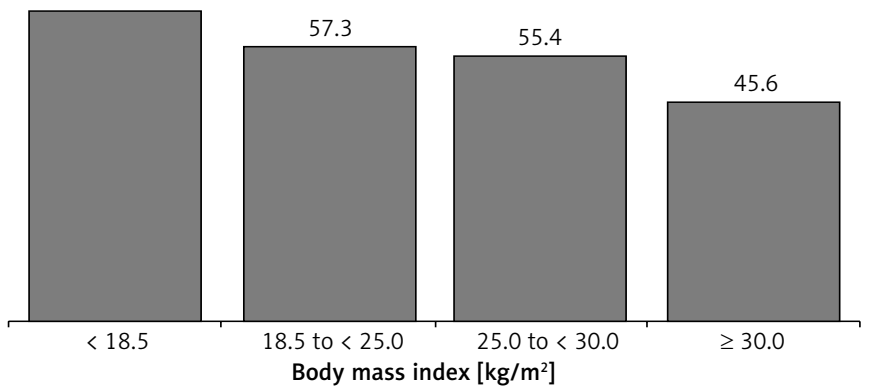

Figure 5. Percentage of REGARDS participants $\geq 80$ years of age with preserved eGFR for whom this result was confirmed using eGFR cys stratified by waist circumference and body mass index

eGFR - estimated glomerular filtration rate using serum creatinine, eGFR - estimated glomerular filtration rate using serum cystatin-C, REGARDS - REasons for Geographic And Racial Differences in Stroke. Preserved eGFR was defined as eGFR $\geq 60 \mathrm{ml}$ $\mathrm{min} / 1.73 \mathrm{~m}^{2}$. High waist circumference was defined as $>102 \mathrm{~cm}$ among males and $>88 \mathrm{~cm}$ among females.

a cohort of 805 old adults (mean age: 80.3 years) from Iceland with a mean measured GFR of $64 \mathrm{ml} /$ $\min / 1.73 \mathrm{~m}^{2}$, the mean $\mathrm{eGFR}_{\mathrm{cr}}$ and $\mathrm{eGFR}$ cys were 68 and $61 \mathrm{ml} / \mathrm{min} / 1.73 \mathrm{~m}^{2}$, respectively [18]. Additionally, in a prior study of adults $\geq 80$ years of age, Van Pottelbergh et al. reported that the mean eGFR was lower when calculated using serum cystatin-C $\left(54 \mathrm{ml} / \mathrm{min} / 1.73 \mathrm{~m}^{2}\right)$ as compared with using serum creatinine in conjunction with the CKD-EPI equation $\left(61 \mathrm{ml} / \mathrm{min} / 1.73 \mathrm{~m}^{2}\right)$ [19]. Our results are consistent with these prior studies and demonstrate that a very high percentage of individuals $\geq 80$ years of age have reduced eGFR based on serum creatinine confirmed when using cystatin-C-based eGFR.

Prior studies have reported that cystatin- $C$ could be used as an additional test to identify a sub-group of individuals with reduced eGFR $_{\text {cr }}$ who have lower risk for all-cause mortality and CKD complications $[13,20,21]$. Peralta et al. reported that reduced eGFR is only associated with higher risk for all-cause mortality if confirmed using serum cystatin-C [20]. Shlipak et al. reported that using cystatin- $C$ as a confirmatory test may rule out reduced eGFR in about $42 \%$ of individuals with $\mathrm{eGFR}_{\text {cr }} 45$ to $59 \mathrm{ml} / \mathrm{min} / 1.73 \mathrm{~m}^{2}$, and that these individuals have a 34\% and 80\% lower risk for all-cause mortality and end stage renal disease, respectively, as compared to those for whom a reduced eGFR is confirmed via cystatin-C [21]. However, the analysis conducted by Shlipak et al. included a small proportion of oldest old (the mean age was 60 years), and the results were not reported stratified by age. Using cystatin- $C$ for the confirmation of a reduced eGFR could be important in circumstances when serum creatinine-based estimations are less accurate (e.g., in those with reduced muscle mass), as suggested by the 2012 KDIGO Clinical Practice Guideline for the Evaluation and Management of Chronic Kidney Disease [9]. There is concern that serum creatinine may be a poor marker of renal function among the oldest old as they may be more likely to have reduced muscle mass or sarcopenia. Unlike serum creatinine, serum cystatin- $C$ is independent of muscle mass and may provide a better estimate for GFR among the oldest old [22]. However, results from the current analysis suggest that measuring cystatin- $C$ for the confirmation of reduced $\mathrm{eGFR}_{\mathrm{cr}}$ is not needed in this population, regardless of their waist circumference or BMI. This is important considering the high prevalence 

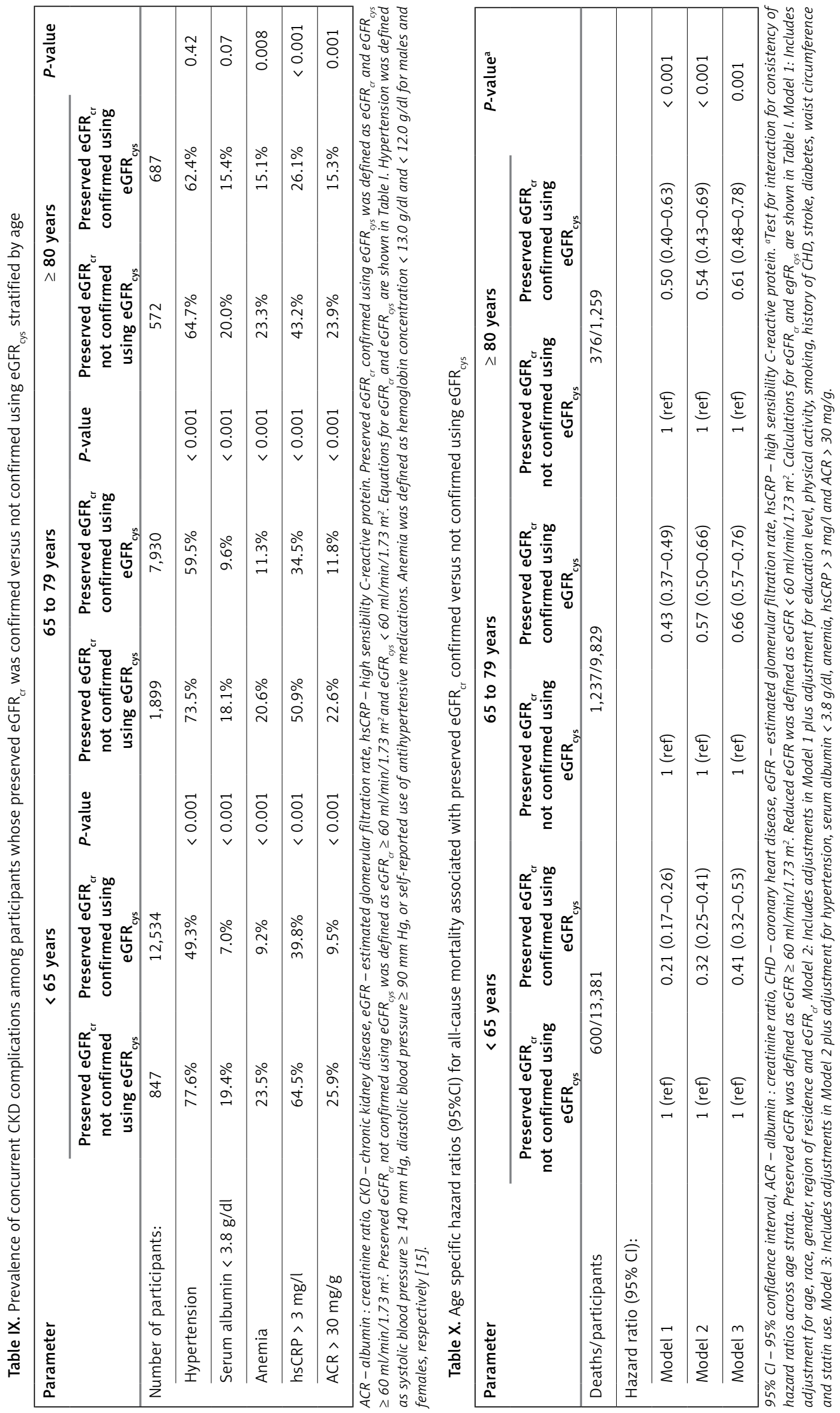
of reduced eGFR ${ }_{c r}$ among the oldest old $[9,23]$ and the relatively high cost of measuring serum cystatin-C [24].

In secondary analyses, we found that $45.4 \%$ of participants $\geq 80$ years of age with preserved eGFR $_{c r}$ had reduced eGFR cys and this proportion was higher as compared with younger adults. Individuals $\geq 80$ years of age with preserved eGFR but reduced $\mathrm{GGFR}_{\text {cys }}$ had a higher prevalence of anemia, elevated hsCRP, and albuminuria and an increased risk for all-cause mortality compared to those whose preserved eGFR cr was confirmed using eGFR ${ }_{\text {cys }}$. Future studies should assess the costs and benefits of measuring cystatin- $C$ among the oldest old with preserved eGFR .

Results from the present study should be interpreted in the context of known and potential limitations. First, eGFR was calculated using data from a single study visit. This may have led to potential misclassification of participants. Second, the observational study design prevents inferring a causal relationship. This is especially important for the cross-sectional analysis of concurrent CKD complications where some conditions may have preceded kidney function impairment. Finally, the REGARDS study excluded individuals residing in nursing homes, which may reduce the generalizability of our results, particularly among the oldest old. Strengths of the current analysis include the large number of participants $\geq 80$ years of age with serum creatinine and cystatin- $C$ measured at baseline. Additionally, the REGARDS study enrolled participants residing in all 48 contiguous states and the District of Columbia.

In conclusion, serum creatinine is recommended to routinely evaluate renal function in clinical practice. However, there is concern that serum creatinine may be a poor marker of renal function at older ages. In the current study, the vast majority of participants $\geq 80$ years of age with

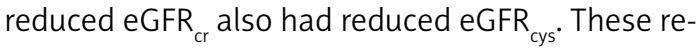
sults suggest that cystatin- $C$ does not need to be measured to confirm reduced $\mathrm{eGFR}_{\mathrm{cr}}$ among the oldest old.

\section{Acknowledgments}

This research project is supported by a cooperative agreement U01 NS041588 from the National Institute of Neurological Disorders and Stroke, National Institutes of Health, Department of Health and Human Service. The content is solely the responsibility of the authors and does not necessarily represent the official views of the National Institute of Neurological Disorders and Stroke or the National Institutes of Health. Representatives of the funding agency have been involved in the review of the manuscript but not directly involved in the collection, management, analysis or in- terpretation of the data. Additional support was provided by an investigator-initiated grant-in-aid from Amgen Inc. to DGW. Amgen did not have any role in the design and conduct of the study, the collection, management, data analysis, or interpretation of the data, or the preparation or approval of the manuscript. Additional support was provided through the National Institute on Aging (R03AG042336-01) and the T. Franklin Williams Scholarship Award (funding provided by: Atlantic Philanthropies, Inc, the John A. Hartford Foundation, the Association of Specialty Professors, the American Society of Nephrology and the American Geriatrics Society) and the US Department of Veterans Affairs (1IK2CX000856-01A1). The authors thank the other investigators, the staff, and the participants of the REGARDS study for their valuable contributions. A full list of participating REGARDS investigators and institutions can be found at http://www.regardsstudy.org.

\section{Conflict of interest}

DGW and PM have received grant support from Amgen Inc. LDC, RMT, OMG, SJ and CBB have no conflicts of interest to disclose.

\section{References}

1. Bowling CB, Sharma P, Fox CS, O'Hare AM, Muntner P. Prevalence of reduced estimated glomerular filtration rate among the oldest old from 1988-1994 through 2005-2010. JAMA 2013; 310: 1284-6.

2. Bowling CB, Sharma P, Muntner P. Prevalence, trends and functional impairment associated with reduced estimated glomerular filtration rate and albuminuria among the oldest-old U.S. adults. Am J Med Sci 2014; 348: 115-20.

3. Bowling CB, Inker LA, Gutierrez OM, et al. Age-specific associations of reduced estimated glomerular filtration rate with concurrent chronic kidney disease complications. Clin J Am Soc Nephrol 2011; 6: 2822-8.

4. Kurella Tamura M, Wadley V, Yaffe K, et al. Kidney function and cognitive impairment in US adults: the Reasons for Geographic and Racial Differences in Stroke (REGARDS) Study. Am J Kidney Dis 2008; 52: 227-34.

5. Matsushita K, van der Velde M, Astor BC, et al. Association of estimated glomerular filtration rate and albuminuria with all-cause and cardiovascular mortality in general population cohorts: a collaborative meta-analysis. Lancet 2010; 375: 2073-81.

6. Muntner P, Bowling CB, Gao L, et al. Age-specific association of reduced estimated glomerular filtration rate and albuminuria with all-cause mortality. Clin J Am Soc Nephrol 2011; 6: 2200-7.

7. Go AS, Chertow GM, Fan D, McCulloch CE, Hsu CY. Chronic kidney disease and the risks of death, cardiovascular events, and hospitalization. N Engl J Med 2004; 351: 1296-305.

8. Malyszko J, Bachorzewska-Gajewska H, Malyszko J, laina-Levin N, Kobus G, Dobrzycki S. Markers of kidney function in the elderly in relation to the new CKD-EPI formula for estimation of glomerular filtration rate. Arch Med Sci 2011; 7: 658-64. 
9. Kidney Disease: Improving Global Outcomes (KDIGO) CKD Work Group. KDIGO 2012 Clinical Practice Guideline for the Evaluation and Management of Chronic Kidney Disease. Kidney Int Suppl. 2013; 3: 1-150.

10. Rosenberg IH, Roubenoff R. Stalking sarcopenia. Ann Intern Med 1995; 123: 727-8.

11. Kim TN, Choi KM. Sarcopenia: definition, epidemiology, and pathophysiology. J Bone Metab 2013; 20: 1-10.

12. Howard VJ, Cushman M, Pulley L, et al. The REasons for Geographic And Racial Differences in Stroke Study: objec tives and design. Neuroepidemiology 2005; 25: 135-43.

13. Inker LA, Schmid CH, Tighiouart $\mathrm{H}$, et al. Estimating glomerular filtration rate from serum creatinine and cystatin C. N Engl J Med 2012; 367: 20-9.

14. Schaeffner ES, Ebert N, Delanaye P, et al. Two novel equations to estimate kidney function in persons aged 70 years or older. Ann Intern Med 2012; 157: 471-81.

15. Kidney Disease: Improving Global Outcomes (KDIGO) Anemia Work Group. Diagnosis and evaluation of anemia in CKD. Kidney Int Suppl. 2012; 2: 288-91.

16. White IR, Royston P, Wood AM. Multiple imputation using chained equations: issues and guidance for practice. Stat Med 2011; 30: 377-99.

17. Sterne JA, White IR, Carlin JB, et al. Multiple imputation for missing data in epidemiological and clinical research: potential and pitfalls. BMJ 2009; 338: b2393.

18. Fan L, Levey AS, Gudnason V, et al. Comparing GFR estimating equations using cystatin $\mathrm{C}$ and creatinine in elderly individuals. J Am Soc Nephrol 2015; 26: 1982-9.

19. Van Pottelbergh G, Vaes B, Adriaensen W, et al. The glomerular filtration rate estimated by new and old equations as a predictor of important outcomes in elderly patients. BMC Med 2014; 12: 27

20. Peralta CA, Katz R, Sarnak MJ, et al. Cystatin C identifies chronic kidney disease patients at higher risk for complications. J Am Soc Nephrol 2011; 22: 147-55.

21. Shlipak MG, Matsushita K, Arnlov J, et al. Cystatin C versus creatinine in determining risk based on kidney function. N Engl J Med 2013; 369: 932-43.

22. Vinge E, Lindergard B, Nilsson-Ehle P, Grubb A. Relationships among serum cystatin $C$, serum creatinine, lean tissue mass and glomerular filtration rate in healthy adults. Scand I Clin Lab Invest 1999; 59: 587-92.

23. Grams ME, Juraschek SP, Selvin E, et al. Trends in the prevalence of reduced GFR in the United States: a comparison of creatinine- and cystatin C-based estimates. Am J Kidney Dis 2013; 62: 253-60.

24. Shlipak MG, Mattes MD, Peralta CA. Update on cystatin C: incorporation into clinical practice. Am J Kidney Dis 2013; 62: 595-603. 